\title{
Citizen Response to Disasters: a Survey of Literature and Some Practical Implications ${ }^{1}$
}

\author{
I. Helsloot* and A. Ruitenberg***
}

It is most likely that the modern citizen responds to disasters in the same fashion as his ancestor. Contrary to widespread belief, citizens do not panic in disaster situations. In fact, research into different aspects of citizen response shows that most citizens act in a rather rational way. Indeed, citizens often prove to be the most effective kind of emergency personnel. Disaster evaluations invariably show that most lives are actually saved by the 'average' citizen. On the other hand, it seems little can be done to improve citizen preparedness. A modern western citizen is not likely to invest time or money in preparing for 'acceptable' risks.

The above results stem for the greater part from research already conducted as long ago as the nineteen-eighties. Limitations and implications however seem as yet unclear. One important limitation is the cultural bias in most studies. One important implication is that in western countries government should step in to improve citizen response by preparing to facilitate it in times of disaster.

\section{Introduction}

Some thousands of years ago, human beings were truly self-reliant: supported only by his next of kin, man had to cope with every and any situation, including disasters. Harsh winters, failing crops or infectious disease could mean a swift demise.

Technological development in the following millennia has increased life expectancy tremendously. To look at recent history: around the year 1800, life expectancy in Europe was around forty years. Today the life expectancy in the same area has almost doubled. The quality of life has improved greatly. Technology brought solutions to many a problem, and many dangers were at least partially eradicated: the industrialised world does not suffer starvation, there are methods for dealing with rising water, and vaccinations provide protection against previously deadly diseases.

However, technology does not protect us from all problems. Safety precautions are (sometimes grossly) neglected at times, technology was not always completely understood, or natural disasters are just too enormous and too unmanageable. Disasters and major accidents will occur.

*COT Institute for safety Secur ity and Crisis Management, Koninginnegracht 26, $2514 \mathrm{AB}$ Den Haag, The Netherlands E-mail: i.helsloot@cot.nl

**E-mail: a.ruitenberg@cot.nl
It is often noted that new technology is in fact the cause of large risks. The hundreds of millions of life-years gained per year thanks to technological advances are taken for granted, and often only negative aspects are highlighted: 'technology also has its dark side. New dangers have developed, which are potentially much greater than the now manageable old risks. The paradoxical development can be seen, where technological advancement places us back in time, because new dangers emerge.' (Sociaal en Cultureel Plan Bureau, 2002). ${ }^{2}$ The scientific discourse on the different possible views in this matter has as well-known opponents Beck (Beck, 1992) and Wildavsky (Wildavsky, 1988).

It is up to both citizens and government to cope with the effects of disasters and major accidents. Not much research is required to understand that it is not possible for government alone to be responsible for all aspects of disaster management. Therefore, some questions need to be answered, e.g. the extent to which citizens are able to respond, whether or not progress can be seen over time, what elements influence the response etc. This article will address those questions.

The following definition of 'citizen response' before, during and following a disaster and major accidents will be used:

'Citizen Response' pertains to all actions taken by citizens:

1. preparing for disasters and major accidents

2. during and after disasters and major accidents 
3. with the intent to help themselves or others to limit the effects of the disaster or major accident

Point three of the definition clarifies the fact that citizen response has two aspects: actions taken for the protection of oneself, and those taken to help others.

The definition purposely does not give any value assessment of the actions. That is to say that some actions, taken with the intent to help oneself or others are taken, do however not necessarily have to be the optimal ones.

This article will focus on the preparation for and the actions taken during the critical phase of disasters and major accidents.

A distinction will also be made in this article between the two elements in the definition of citizen response: the preparation for, and response to disaster situations.

Already at this point, an important limitation of the used research has to be observed: cultural relativity. All researches took place in the western world. In some instances, this limitation will be explicitly mentioned, by pointing out the Bhopal disaster in India, and the earthquake earlier this year in Morocco.

\section{Citizens and their Preparation for Disasters and Serious Accidents}

The core result of this section is not very surprising: citizens prepare for those accidents that they perceive to be a significant threat. 'If men define their situations as real, they are real in their consequences', thus Thomas and Thomas postulated as early as 1928 (Thomas \& Thomas, 1928). Thus, insight into public perception of security risks is the first necessary step towards understanding citizen disaster preparation. (Figure 1)

\section{Public Perception of Security Risks}

It is fairly redundant to state that public perception of some security risks has changed radically over the last 30 years. This might be most visible where it concerns large-scale accidents: whereas 1835 deaths caused by the 1953 Flood in the Netherlands were largely perceived as an 'act of God' beyond the responsibility of government authority, the 22 deaths resulting from the explosion of a fraudulent fireworks depository in Enschede, Netherlands, were just as largely perceived to be an unacceptable and essential failure of the government.

It is therefore all the more striking how other (objectively speaking, larger) risks are still assessed by the public at the same risk-level, and are still generally accepted: e.g. the unchanged chances of being involved in a traffic accident.
Also, the risks of smoking have become more apparent over the last thirty years; smoker numbers, however, have been more or less stable throughout the same period. For this reason, of topical interest to policy makers and communication scientists has been the question: what influences the public perception of security risks, and how can such risks be communicated?

A wealth of research has shown that citizens look at more than just 'chances' or 'effects' of risks when they assess security risks. In fact, such measures play a minor role when assessing the acceptability of security risks. This is already demonstrated by the mundane examples mentioned above (traffic participation or smoking)(as well as the fact that communication about these risks will always have a limited effect). Starr was the first to attempt to systematically research public perception pertaining to the balancing of advantages of actions versus the security risks attached thereto (C. Starr, 1969) Thus he concluded in 1969 for example that the acceptance of risks voluntarily taken (like traffic participation and smoking) is a thousand times as probable as the taking of risks taken involuntarily. Subsequent research done by Slovic et al. in the US (Slovic et al, 1979) and Vlek \& Stallen in the Netherlands (Vlek \& Stallen, 1980) indicates that a number of (sometimes combined) aspects of risk influence the perception thereof:

- the 'catastrophic potential' or 'perceived threat'

- involuntarism understood as unfairness (who benefits, who bears the effects)

- involuntarism understood as a lack of personal influence (uncontrollability)

- new risks versus known risks (e.g. new technology)

- hidden or long-term effects of the risk (e.g. cancer after long term exposure)

- lack of clarity of the societal effects of the riskbearing activity.

In recent years, research has shown that the following factors also influence risk perception:

- confidence (or the lack of it) in the openness of responsible institutions

- attributability of the risk, as in the consciously criminal or unsafe behaviour as cause of the occurring incident.

However, a consistent model of all of the factors mentioned above, allowing for predictions, has yet to be developed. ${ }^{3}$

\section{The Meaning of Risk Perception}

Citizens only prepare for the kind of threat they perceive as 'imminent'. Also, the kind of risk must 


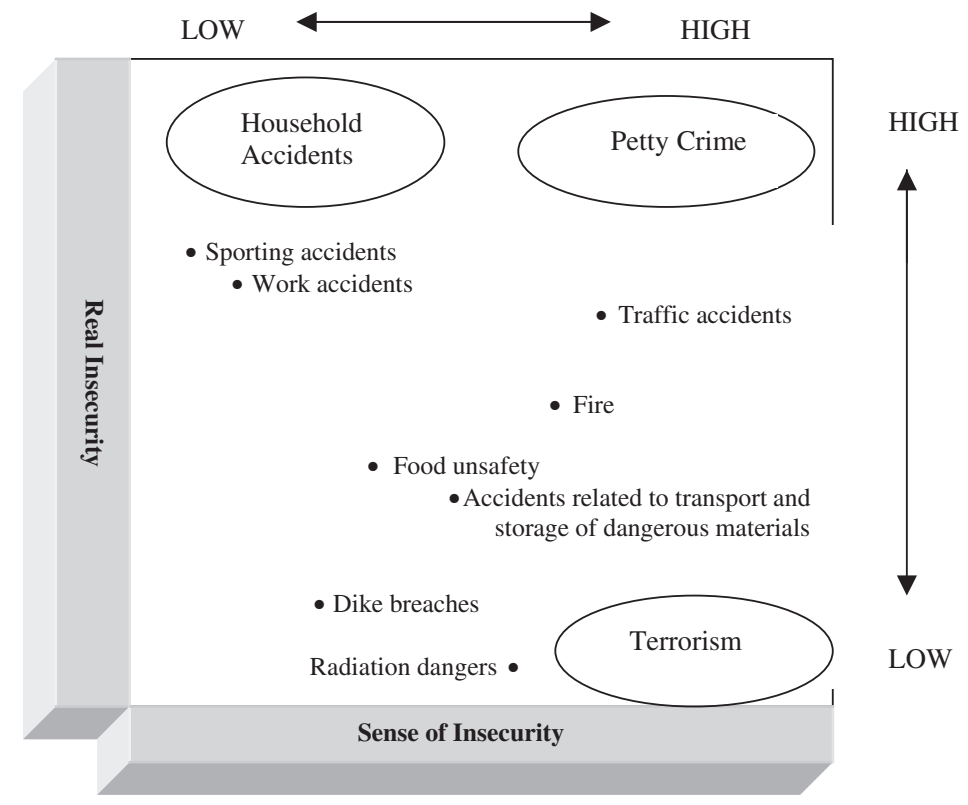

Figure 1.

(Source: Rosenthal \& Staal, K.J. Storm, 2002)

be one worth the preparation. This helps them to feel in control of the perceived threat (Major, 1999).

Just as risk is a social construct which cannot be objectified (see above), the preparation for disasters and serious accidents is directed by the perception of the threat.

It must be noted that some authors do in fact mention 'rational' reasons for not preparing for disasters. In this case, the citizen does not prepare because, firstly, the actual chance the disaster will happen is assessed as being too low to deserve preparation, and because secondly, the citizen believes he/she does not have enough information about potentially effective preparation strategies (Tierney, 1989).

Research attempting to show the motivation for citizens to prepare for disasters has been done with different approaches, which correspond to the different aspects of risk perception of the individual citizen: the nature of the threat, experience with disasters, sex, and the socio-economic status of the citizen.

\section{Nature of the Threat}

In the case of potential natural disasters, citizens often base their assessment of risks on sensory perception. These risks are visible and finite in the citizen's perception. If necessary, they take action to protect themselves (look for high ground, a safe area etc.). In the citizen's understanding, preparing to respond to these kinds of disasters makes sense.

The distinctive characteristic of 'new' risks resulting from technological innovation is that it concerns the potential effects of human action, of which the full nature and effect are unknown. Citizens perceive these effects to be catastrophic, irreversible and with long-lasting effects. An example could be the danger of radiation. It is an intangible, time-unlimited and deadly threat, which can come from all directions, and against which protection is difficult or impossible. Factual information about radiation levels and the real threat of it is often absent. Citizens have been exposed to many discussions and information about the harmful effects of the radiation. For these reasons, whenever radiation comes into play, it is perceived as a threat of high level radiation threatening with serious health problems or even death. To prepare for this kind of threat is quickly dismissed as futile.

\section{Experience with Disasters}

Communities which have more than once been hit by certain types of disasters often develop so-called 'disaster subcultures', in which the exchange of knowledge, exercises and other preparations are of central importance. In communities with such subcultures the reaction to disasters is often swifter and more adequate. Personal experience with dangerous situations often results in more accurate perception of danger, however it does not mean a more extensive preparation for other possible dangers per se. These subcultures are often directed at only one type of disaster, and cannot always cope with other disasters. For this reason it cannot be said that when a community is prepared for one type of disaster, that it is therefore prepared for all kinds of risks (Tierney, 1989). 


\section{Sex and Socio-economic Status}

Research has been done into the different ways men and women communicate about risks or the way in which they receive risk-related information. What the resulting difference in risk perception means to the preparation for disasters, however, has not been researched (Major, 1999). Perry and Mushkatel indicate that awareness of threat and the preparation for it can be related to socio-demographic characteristics (e.g. income, education, ethnicity) (Perry \& Mushkatel, 1986). Generally, non-minorities and people of higher socio-economic status are better prepared for disasters and serious accidents than others: 'Minorities experience greater relative difficulties than whites because they have lower incomes and money reserves, are more likely to be unemployed, less likely to have disaster insurance, and more likely to have problems communicating with institutional providers of information about disaster risks and post-impact relief' (Tierney, 1989; Fitzpatrick \& Mileti, 1994). Note that there is an essential difference between 'being prepared' and 'preparing'.

\section{Citizen Response During Disasters}

Citizen response during disasters can be broken down into the alarm stage, acute stage (actual response aimed at rescue, medical aid, shelter, etc.) and the recovery or rebuilding stage. The last stage will only summarily be discussed in this Article.

\section{Alarm Stage; Citizens Take Critical Decisions}

In the alarm stage of the disaster, citizens must make a number of decisions. They listen to the radio advising them to close windows and doors, to avoid certain areas or to even be evacuated. Neighbours and family call with other information. Citizens receive these and many other forms of information, and must then decide whether or not the information is trustworthy and whether the advice given is relevant to them.

Whether or not measures are taken relies therefore on the interpretation of the situation by the citizen (Perry, 1985). A number of logical steps are taken from the moment the warning has been received. These steps are not taken in direct linear sequence, but strengthen or weaken each other as the individual decision making process unfolds. New information leads to reassessment of the situation (Fitzpatrick \& Mileti, 1994).

Research has repeatedly shown that the departure point for thinking about the response lies at the moment the threat is perceived as 'real': 'unless the warning recipient believes that the threat is genuine, he is not likely to undertake any protective action' (Perry, 1985). Two factors play a role:

- The citizen assesses the reliability of the authorities or others that issue warnings. A factor in this case is for example the number of times a false alarm has been issued.

- Then the confidence put in the information depends on the predicted location, time and possible scale of the announced disaster. In that case, analogies are made with earlier personal experiences with the announced type of disaster.

Citizens who deal with information they perceive as unreliable, will, as in daily life, look for confirmation and verification. This is one of the explanations for the heavy phone traffic just before and during disasters (Fitzpatrick \& Mileti, 1994).

When the message is understood as realistic, the recipient will then wonder what the message means to him/her and his/her social surroundings (family, friends). As posited above, the available information about the disaster is of great importance. Only when the recipient is convinced that the effect of the threat will harm him will be consider responding to it.

The following factors come into play when a citizen decides whether or not to take protective measures (Perry, 1985):

- Does the warning leave enough time to react to the disaster impact?

- What is the family situation? Generally families hesitate longer when not all members are safe or gathered together. In evacuation situations, families often act as a group, not as a collection of individuals. They wait for each other in order to be able to leave together for example. This can cause problems when time is of the essence.

- The availability of a 'safety plan', which enables individuals to take precautionary measures.

\section{Actions of Citizens When Confronted With Disaster}

People use two different systems when deciding how to act when confronted with disaster: intuitive and analytical. The former is the swift, associative, affectionate, automatic, emotional and unconscious. The latter is based on rules of reasoning, algorithms and formal logic, but is slower and calls for more effort, learning capacity and consciousness. Neurological and other studies have shown that both these systems with their respective advantages and disadvantages, distortions and limitations are used to come to decisions. When the two processes point in different directions, research shows that the as- 
sociative, affective processes often make the difference, especially in the case of time pressure (Slovic 2000).

Citizens react quickly and intuitively in case of a lack of preparation time and sudden occurrence of the disaster, as with acute disaster such as earthquakes, storms, terrorist attacks. Generally, they respond adequately. This greatly negates the general ideas of citizens and authorities. There are three well-known myths about citizen response that can be dismissed on the basis of research done as long ago as the nineteen-eighties. However, these myths still prove to be the basis for governmental preparation on disasters.

\section{Myth 1: Citizens Panic in a Disaster}

The initial fear instilled in citizens in an emergency quickly subsides as they start to look for ways to secure their own and others' safety. Those who address initial aid are bystanders, relatives or other people who happen to be present. Others make sure that they leave the disaster location in a direction they deem safe at the time. In contradiction to images provided by disaster movies or media reports, people almost never panic. If panic occurs, it affects only a small number of people, and it lasts only a small amount of time (Perry \& Lindell, 2003; Quarantelli, 1999; Dynes, 1994).

The emergence of the panic myth is explained by Perry and Lindell with two sources (Perry \& Lindell, 2003):

First, when victims describe their own reaction to the disaster they often call it a "panic reaction" ("When I saw smoke in the room, I panicked"). Research shows that actual behaviour does show an acute reaction of fright ("I was startled and frightened by the smoke hanging in the room"), which is followed however by rational and often altruistic acts ("I grabbed the baby and ran outside, just before the house caved in").

Second, researchers, journalists and onlookers wrongfully interpret the actions of victims who were unsuccessful. A news report about victims of hotel fires who have been found dead in the bathroom or hall, will state that these people fled to the toilet in panic. A more plausible explanation however is that - because of lack of visibility due to smoke - they entered the first door in the hall, thinking it to be an exit. Upon realising this mistake, it is too late to go back to the hall, and they decided to wait in the bathroom. In short: the fact that an error of judgement was made, resulting in death, does not mean that the error was due to panic.

It should be remembered that no scientific consensus exists about the use of the term 'panic'. The scholarly discourse roughly discerns two different views. The oldest vision, coming from daily use of the word, equates panic to an extreme and unfounded fear. The other opinion sees panic as a manifestation of flight behaviour, in which the usual social norms are openly abandoned (e.g. parents abandoning their children to save themselves) (Quarantelli, 1999).

In both views there are two central themes (Quarantelli, 1999):

- Panic behaviour is irrational. This view has become heavily criticised, especially by those researchers who have conducted empirical research on the behaviour of people in disaster and fire situations. These researchers conclude that behaviour in such situations is in fact very meaningful and far from irrational - from the viewpoint of the people affected.

- Panic behaviour is contagious. People supposedly mimic panic behaviour very quickly. Again, empirical research shows this to be incorrect. If panic occurs in exceptional cases, this panic, whatever kind, is mimicked by only a very few.

Thus, panic reactions are very rare, but they do occur. Four conditions that can cause panic are to be observed (Perry \& Lindell, 2003):

- The perception of immediate and serious danger

- The perception of availability of only a few escape routes

- The perception that the escape routes are closing, making immediate escape necessary

- The lack of communication about the situation

These conditions together pose a threat from which, in the perception of the victim of panic, there is no rational escape.

\section{Myth 2: Citizens are Helpless and Dependent}

In disasters, citizens are generally not at all helpless or dependent on help from outside. As far as possible, these are the first to start search and rescue activities, victim care and reconstruction.

"As a whole, human beings respond well at impact times of disasters. People in such situations actively seek relevant information and attempt to do what they can to deal with the exigencies presented by the emergency. The threat of a disaster just about to happen or its actual impact does not paralyse those affected. Passivity in the face of danger is almost non-existent" (Quarantelli, 1993).

"Most citizens do not develop shock reactions, panic flight occurs only rarely and people tend to act in what they believe is their best interest, given their limited understanding of the situation" (Perry \& Lindell, 2003).

"Survivors do so much prior to, and separate from, the actions and directions of officials that 
it sometimes leads emergency agency personnel to mischaracterize the activities as confused, chaotic and random" (Dynes, 1990).

Also, it is often wrongly assumed that victims and evacuated persons are dependant on the help of government or private organisations for shelter after the disaster. In fact, most victims go to family and friends under their own steam (Tierney, 1989).

\section{Myth 3: Looting Occurs During and After a Disaster}

A very strong myth is the one stating the occurrence of looting shortly after disasters or serious accidents. Quarantelli discredited that myth as long ago as 1969 (Quarantelli \& Dynes, 1969). Since then, he has stated on the basis of empirical research that looting almost never takes places at those times. In the rare cases it does occur, it is done by lone individuals from outside the community (Tierney, 1989; Quarantelli, 1993).

Authorities often do take measures to prevent looting. Also, the media often report looting during and after the disaster. These stories often even occur amongst aid workers.

It is possible the research cited here was culturally limited. Indeed, Lapierre and More note, based on eyewitness reports, that not only after, but also during the poisoned gas emission at Bhopal in 1984, where 30,000 people died, systematic looting occurred, even manslaughter (Lapierre \& More, 2001).

\section{Situational Altruism as a Special Instance of Citizen Response}

The willingness of people to assist with disasters and serious accidents is generally rather abundant. Not only directly involved citizens (such as family and friends) but also others. This behaviour directly following the disaster, which is a special instance of citizen response as defined in this article, is so widespread that it has been labeled as an "informal mass assault". There is a very large involvement of the community directly after the disaster. Even after the most serious disasters and serious accidents there are often more non-victims than victims in the area, which enables the community to adjust itself (Tierney, 1989). Just after the earthquake in Kobe, Japan (1995), inhabitants did most of the rescue work. Official emergency services only found about a quarter of those who were pinned down and saved. The earthquake had a devastating effect on the communication between emergency services: phone-lines did not work, serious damage was done to radio and fax of the prefecture, and backup facilities for key functions were lost (Hiroi,
1995). Massive aid followed spontaneously. Estimates of volunteer aid workers during the subsequent months range from 630,000 to 1.3 million people. Explanations for this have been found in e.g. the fact that its necessity was quite clear, the intense media coverage and the classfree period, enabling many students to help (Tierney, 1997).

Dynes calls the massive aid provided by citizens coming from afar "situational altruism". He posits that it occurs in the situations where 'new' victims occur, and a doubt exists as to the possibility that institutional organisations can handle it. He discerns three forms of direct aid (Dynes, 1994):

- The emergence of short term functions: the 'mass assault' of collective response during and shortly after the impact of a disaster. The Disaster Research Centre of the University of Delaware found in a study of the Mexico City earthquake (1985) that $10 \%$ of the population was involved with volunteer work directly related to the earthquake. This means that around 2 million volunteers were active at the time.

- The activation of family and relatives. Relatives inform themselves of the status of the possible victims in the area, directly following the disaster. They are prepared to offer help immediately with the means available to them.

- Situational altruism is especially strongly expressed within local organisations and companies. Contrary to the general assumption that they function worse after a disaster, they do in fact offer many services:

- Organisations involved work extra hours

- Organisations involved have extra capacity due to the use of volunteers (e.g. the Red Cross)

- The involvement of 'new' organisations (e.g. the national petroleum company helped with rescue activities in 24 different locations after the 1985 Mexico City earthquake).

Situational altruism motivates people to help in ways that are not mentioned in contingency plans. This creates opportunities for organisations and helps let them work more actively. It promotes the transfer of goods, and the response to needs. It strengthens and helps victims to supply basic necessities. On the other hand however, it also causes personnel, citizens, goods and services to come together at the same time, which can cause chaos and lack of clarity. It can also cause competitive behaviour by those who help victims (Dynes, 1994). Situational altruism can be seen as a special kind of emergent norms that are guiding citizens (and responders) in 
times of disasters (Dynes and Quarantelli, 1968, Stallings and Quarantelli, 1985).

Research into the earthquake in Erzincan, Turkey, 13 March 1992, indicates that fast citizen response aimed at the rescue of others is not always to be expected. Two thirds of the citizens of Erzincan saw relatives who had serious injuries or had died during or shortly after the earthquake. The community had been confronted with a catastrophe, which had traumatic effects on those who survived. In such circumstances, it is not entirely surprising to have a lack of response, or slow response time in the first hours after the disaster. A disaster of such magnitude can have a strongly disruptive effect on a relatively small community, due to close family, social and economic ties (Comfort et al., 1998).

However, after the earthquake in Morocco in 2004, TV images and stories of members of rescue teams seem to indicate something else: the huddling of groups of hardly affected citizens around the remains of a small limestone house, allegedly covering victims. These people were passively waiting for rescue workers to arrive, who had to remove the remains without any help. As remarked before, culture may have a greater meaning for citizen response than has yet been accounted for.

\section{The Anticipation of Authorities to the Behaviour of Citizens prior to and during Disasters}

There are different ways in which authorities can cope with citizen response and its preparation or encouragement. The fact that disaster management was originally based on militarily organised civil defence organisations has had a lasting impact on the world - to different degrees depending on the country - to this very day. It is partly based on assumptions which have proven to be wrong by scientific research. These assumptions however do have an effect on the ways in which governments prepare for disaster management and risk communication, and especially on the role that citizens play in this.

\section{The Acts of Governments in Preparation for Disasters and Serious Accidents, Related to Citizens ${ }^{4}$}

Since the Second World War, in many countries disaster management has been organised under the heading of civil defence. This policy was logically based on military ideas. The underlying assumption was that disasters should be seen as an enemy, and approached as such. Dynes notes that the planning for the construction of civil defence is based on the military doctrine ' $C^{3 \text {, }}$ (Chaos, Command, Control). The starting point of this line of thought is the idea that disasters cause 'chaos' and that 'command' and 'control' are the means to reduce the situation to regular proportions. Paramilitary organisations, or organisations which work according to military command structures, are most suitable to cope with disasters, according to this model. Regular civil institutions are assumed not to be able to cope adequately with emergency situations, due to the vulnerability and ineffectiveness of their respective 'command' structures.

Over a number of years, the $\mathrm{C}^{3}$ model has been undermined by co-operation amongst different governments, and the emergence of advising institutions. Since the end of the nineteen-seventies the focus has been more and more directed towards civil emergency operations by aid organisations in close contact with local and functional governments. In the nineteen-eighties the whole western world has seen a dramatic shift from civil defence to disaster management. However, the paradigm of the war analogy still stands, mostly because it is simple and clear (Gilbert, 1995).

This is also true for the current disaster management structures, in which some elements of the $\mathrm{C}^{3}$ model still remain:

- There is a relatively large amount of attention paid to the anticipation of and controlling of anti-social behaviour in the chaos of a disaster (such as looting, aid workers helping their own relatives first etc.);

- There is a reluctance to use conventional means of communication in the case of disasters (those involved have a plurality of phones or walkie-talkies );

- It is assumed that citizens are not capable of collecting correct information, and therefore need to be informed (e.g. press conferences, official statements of authorities);

- It is assumed that victims are passive and cannot take care of themselves. A large part of disaster management in its acute stages is attributed to the solving of problems of victims;

- There is a general mistrust of the independent actions of volunteers or groups which spontaneously emerged, which were not accounted for in the original contingency plans. Spontaneous actions are not perceived as controllable, and as such seen as irrelevant of disruptive.

Dynes juxtaposes the militarily oriented $C^{3}$ model to a different concept, which also consists of three C's: Continuity, Co-ordination, Co-operation. $\mathrm{He}$ proposes the following:

- Emergencies cause a certain amount of unrest and disorganisation, but not social chaos

- Emergencies do not reduce the capacity of individuals or social structures.

- The use of existing social structures is the most effective way to solve problems related 
to emergencies. The creation of artificial structures is not possible and not effective.

- Planning serves to let people come to rational and balanced decisions in acute situations.

- An emergency can be characterised by decentralisation and plurality of decision making processes, which makes the autonomy of decision making valuable. Centralisation of decision making is not.

- The focus must be aimed at solving the problem, not at the prevention of chaos.

Dynes estimates it is very possible that without planning, people probably develop a more effective reaction to emergency situations than if they bear the burden of the assumptions of the command and control model.

Dynes's three C's can be characterised as follows:

\section{Continuity}

The best predictor of behaviour in emergency situations is the behaviour prior to the emergency situation. In case of emergency, the existing structures must be used to their fullest extent, artificial structures as little as possible. This model does not assume that people will behave passively or irresponsibly in emergency situations. Decisions do not need to be made for them, they can be made in co-operation with them. Examples: warnings must be in a language and form that are comprehensible to those addressed; routes of evacuation must be planned along regular routes, etc.

\section{Co-ordination}

This is achieved through the normal planning and repetition activities, the establishment of personal contacts, development of liaison structures and shared operational facilities for emergency situations. Planning for emergency situations must be aimed at demands directly from the field, instead of at the demands from a go-between actor. This will bring the focus at the process. The advantage of this model is that it allows for improvisation in the response phase. This approach is not the now fashionable method by which emergency plans are filled with detailed information on the proper behaviour in any and every conceivable hypothetical situation. Such trivial information is the logical effect of a military approach, in which improvisation stands for the failure of adequate planning.

Without allowing for improvisation, emergency planning loses its flexibility in the face of changing circumstances. However, without preparation, contingency planning loses its clarity and precision. Preparation and improvisation work in synchronisation.

\section{Co-operation}

Organisations which are based on the paramilitary model have difficulty incorporating volunteers, because they do not fit into the rank or authority structure. On the other hand, volunteers can contribute significantly to the general effort. The central focus of planning must not be aimed at 'control' but at the effective distribution of human and material resources to the community. The systematic development of response systems for disasters is well developed in those communities which are exposed to certain risks (such as seismic dangers). However, the actual occurrence of the disaster can deviate from the prepared plan. The challenge of mobilising response, the delivery of material and the organisation of shelter and medical care for thousands after a sudden destructive event is a dynamic, interactive and unpredictable process. The rate of success of an effective response system depends on the possibilities of training, means, material and infrastructure prior to the disaster (Comfort et al., 1998).

\section{Structuring Citizen Response}

A number of countries have founded organisations to structure Citizen Response. The Englishspeaking countries are leading the way in this. In New Zealand, 'Recovery Managers' are trained to supervise local committees recovering from disaster. In the US 'Community Response Teams' (CERT) are composed. These teams consist of local residents. In the course of a number of meetings, they are trained in the necessary life saving skills, and the doing of "the greatest good for the greatest number". Such teams are intended to be an extension of profession aid services and are expected to proved aid immediately following disasters or heavy accidents, until the professional aid services arrive (FEMA, 1999).

These teams are founded with the thought that after a great disaster, those aid workers arriving first will not be able to address the great demand for help. The number of victims, communication problems and blocked roads obstruct aid. Citizens must be able to rely on each other for the immediate life saving tasks. Under these circumstances, relatives, colleagues and neighbours will offer help to each other spontaneously. This happened directly following the earthquake in Mexico City, where untrained citizens volunteered and saved 800 people. However, 100 people died as a result from trying to save others. This high price can be greatly prevented by training and preparation, or so brochures about the team claim. With recruitment texts based on the above, and an appeal to patriotic feelings, US citizens are encouraged to take part in such training (FEMA, 1999). 
Research on the effectiveness of such teams, however, seems still to be absent. Results of some twenty interviews with professional aid workers from Fairfax (Virginia), Washington, D.C. and New York in January 2002, conducted by one of the authors of this article indicated however that there was a total lack of co-operation and trust from the side of professional aid workers towards such teams.

\section{Checklists}

There are a number of checklists for Citizen Response. These are aimed at the local government (e.g. the 'disaster resident communities' programme of the FEMA), but also aimed at companies (e.g. the world-wide checklists for the preparation for the turn of the millennium), and citizens themselves. The terrorist attack of 11 September 2001 has greatly boosted citizen response. Many instruction booklets and brochures were developed and communication programmes were started to get citizens more involved in the preparation for disaster management.

Mostly in Western countries, local, regional and state governments prepare themselves for such events, and inform citizens about it. ${ }^{5}$ Based on overviews of risks, special guidebooks are prepared for citizens. In these, citizens are informed about how to prevent accidents, as well as about what to do during disasters. The contents of such brochures are very concrete. It is explained what types of disaster can occur, and what specific measures can be taken. Citizens are also informed what they should always have ready to survive in disaster situations.

The style and tone of the brochures differ between countries. In the US a lot of attention is paid to concrete checklists and there are very few photos or illustrations. The rare illustrations depict a happy family, which suggests a complete preparedness for disasters. A typical brochure in New Zealand however, shows a parent fleeing with child, with the line: "Will you cope when disaster strikes?" Multiple pictures of flooding, earthquakes and sheltering frightened people fill up the space next to concrete information about storms and other types of disaster.

No known research has been done into different effects of the different checklists, instruction booklets or brochures on risk consciousness or on the possible initiated preparation of citizens for disasters, serious accidents or terrorist attacks.

\section{Implications for Disaster Management in the Acute Fase of Disaster}

In the first hour after an acute disaster or serious accident, fire department, police, medical aid workers and other government organisations involved are mostly working on the starting up of their own disaster management organisation (Kuipers \& Meuleman, 2003). However, for seriously injured victims in the disaster area, the reception of aid during that first hour can be the difference between life of death. For this reason, this time is also known as the 'golden hour'.

It takes time to act in a structured way on a large scale. In that first period following the disaster, citizens will mostly have to rely on themselves and spontaneous aid. Thus after the fireworks explosion in Enschede, Netherlands, between 15:30 (the moment of the fatal explosion in which 22 people died) and 16:10 no firefighting took place. The prime effort made was the buildup of a large scale disaster organisation. Only from 18:30 onwards was there any large scale and structured fire fighting effort (Commissie Onderzoek Vuurwerkramp, 2001).

The planning of governments, however, almost never leaves room for aid provided by citizens. From evaluation of disasters (in the western, industrialised world), it is shown time and again that those who are providing initial aid are those citizens present at the disaster. Shortly after the disaster, aid from relatives and other citizens follows. As an example, in Japan too, the government had not provided for facilities or plans dealing with citizen response in the earthquakes of Hanshin-Awaji and Kobe: "However, volunteer activity, not having been foreseen, was not included in the Plan and, as such, there was, initially, some confusion over which departments should be in charge of volunteers and their specific activities" (Hashimoto, 2000).

The observation that it is mostly citizens who provide aid in the first hours is not new. With the train disaster on the 8 January 1962 in Harmelen, Netherlands, a total of 93 people died, and 54 people were injured. Immediately following the collision of the two trains, aid was initiated by survivors and those living in the vicinity. 'However, after an hour the group of volunteer aid workers had grown to such an amount, that it created problems with communication and COordination.' (Rosenthal, 1984). The same happened on an incomparably larger scale in Turkey, 17 August 1999 in the city of Golcuk, where 17,000 people perished: 'A traffic jam of 32 kilometres of spontaneous aid volunteers blocked professional aid workers and rescue vehicles to get to the disaster location', and 'Too much help made a mess here. But you can't stop people from coming' (ICRC, 2001).

The negative terms used about the volunteer work offered are striking in the quotations above; it mostly hinders the professional aid workers who show up in the first hours. The International Red Cross for example does not consider the aid of volunteers helpful, unless it is organised and co-ordinated well (ICRC, 2001). Evaluations 
acknowledge the importance of citizen response, which is in great contrast to the limited promotion of citizen response (Wenger \& James, 1994). Even Qurantelli while noting the importance of civil response for emergency medical aid ('first aid') would like to see more coordination of professional emergency medical aid in these crucial hours (Quarantelli, 1989). In fact, it can put more strongly, as can be deducted from interviews held by the authors; emergency personnel and authorities even have a negative perception towards the activities of individual citizens.

In order to obtain a correct assessment of the value of citizen response in the critical phase, a closer distinction of the available knowledge and skills of the volunteers needs to be made, and the phases and activities during the disaster need to be specified. Such distinctions will be made in the following section.

Here, it will suffice to state that some evaluation reports call for more attention for a certain kind of citizen: the professional aid worker who is not on active duty or comes from a different area. These aid workers report spontaneously during disasters and serious accidents as well. The reception of and assigning of tasks to these people are usually also neglected. ${ }^{6}$

After the initial phase of a disaster, in which acute life-saving aid and relief is necessary, a much longer recovery phase follows. In this time period, victims have to be helped to resume their everyday lives. In these stages too, the role of volunteers is important. And, as in the other phases, governments generally fail to take into account the availability of the responding citizen. However, as there is more time to consider citizen response as an option, a positive appreciation can be developed, and consensus can be reached on how to use the responding citizen.

\footnotetext{
"The success of relief efforts by those spontaneously offering their help depends on the capacity of agencies and authorities to integrate them quickly and effectively into a coordinated strategy. One reason for the success of Kobe's volunteers was the way in which local authorities and volunteers eventually developed complementary functions. For example, while the government concentrated on repairing infrastructure, volunteers built and managed the day-to-day running of temporary shelters" (ICRC, 2001).
}

\section{Distinguishing Citizen Response by Disaster Type and Disaster Management Process}

Here a concrete modelling of disaster types and disaster management processes will be presented which can be used to evaluate citizen response in the acute phase of a disaster.

Disaster types describe what is seen as separate and different types of disaster. Disaster management processes describe the different types of activities that can be distinguished during disaster management. The research for this article has analysed the classical 18 disaster types and 31 disaster management processes presented in the guidelines of the Dutch government in order to find out which forms of citizen response are possible, and in which way they can be motivated. This research then further condensed the groups of disaster types and processes into groups which have similar implications for citizen response.

The following (partly overlapping) division of disaster types can be made:

- The classical 'flash' disaster: serious transport accidents, fire, explosions, etc.

- The release of dangerous substances or contagious agents

- Natural disasters with a warning period

- Disaster involving crowds

- Failure of public utilities

\section{The Flash Disaster}

The classical 'flash disaster' can be described as an unexpected and immediate occurrence of an accident, where at least some 10 victims occur. In these cases there is an almost inevitable shortage of emergency personnel who can help all victims within the first minutes to half an hour. Realistic times necessary to bring about the necessary potential are at least an hour. Thus, victims have to rely on themselves and other citizens for at least the first hour following the disaster. As shown above, this kind of aid is in general effectively provided.

It is clear that risks are taken, especially during rescue operations undertaken by citizens. In some cases (such as the earthquake in Mexico City, and the Oklahoma City bombing), this resulted in documented fatalities. But it is just as clear that more lives were saved during these activities than were lost. Emergency personnel, interviewed by the authors, emphasised the dangers that these kinds of citizen response can entail, the practical impossibility of co-ordinating these efforts and the possible liability of the government it entails.

One of the most crucial problems of a 'flash' disaster is the limited capacity of medical aid. However, it is very likely that in populated areas one or more medically schooled persons will be present. This group is varied, ranging from people with a simple First Aid diploma to physicians. The aid that these medically trained citizens can 
provide can be dramatically improved by providing the correct medical materials.

When the assessment is made that this form of citizen response can save human life, it is preferable to take this into consideration when training and educating emergency personnel, and to accept the liability as a government. It is then preferable to enshrine this liability in legislation (in the Netherlands for example that would mean an expansion of the Act of Liability in Case of Disasters and Serious Accidents, which is currently entirely aimed at aid workers).

\section{Release of Dangerous Substances}

Some types of disaster bring with them a release of dangerous substances, which threaten public health. In the acute phase, this means that the part of the population which is in the immediate risk area must respond by moving away from the area. Aid must be provided to the more feeble fellow citizen. This subject will be treated more thoroughly under the headings 'warning the population' and 'evacuation'.

Those citizens who are not immediately endangered will evacuate spontaneously, as soon as there is a perception of risk. This spontaneous evacuation can seriously hamper any organized evacuation and the arrival of relief organisations. It therefore seems preferable to supply information on a more individual basis. However, there is no empirical research on this.

A limited contamination of the environment of the population has the predictable effect of communication and other problems: citizens who quite reasonably want a minimisation of the unwanted risk will demand measures which 'objectively' speaking are not cost-effective. Citizen response will than transform into interest groups and legal procedures.

In the case of minor contamination (not an immediate threat to public health) and/or in the case of an exposure to the contamination by large areas, it can be preferable to have the population decontaminate itself. These issues will be treated in greater detail in the discussion of the processes of warning the population and decontamination.

\section{Disasters with a Warning Period}

Disasters which provide an warning period tend to be natural disasters. The warning period may vary from some tens of hours to some days. One can imagine such disasters as forest fires, floods and extreme weather conditions.

In the warning stages, individualised advice to, and an appeal to citizens response is possible and necessary. The citizens involved will understand the urgency of the threat (if well communicated) and will be able to take the appropriate action.
In the disaster management phase, citizen response will be just as necessary due to the scale of the disaster. Many of such actions will be undertaken by professional citizens, who will often also have more and better material at their disposal than the government: contractors, contracting firms, foresters, etc.

\section{Disasters Involving Crowds}

Disasters involving crowds can result in a great number of victims, for the simple reason that they involve a high concentration of potential victims.

It is, however, generally known in advance that the crowd will form. The presence of a certain percentage of, for example, emergency personnel and medically trained citizens can be used to advantage in the event of a disaster provided that the right equipment is made available.

\section{Failure of Utilities}

The failure of utilities can have (in the case of longer periods) a seriously debilitating effect on society. It is evident that the government does not possess the means to limit the effects adequately. Citizen response is therefore necessary. Relief work can partly be done by professional citizens (both inside and outside the context of a company), who can access specialised material.

In practice, this already happens spontaneously. However, without the co-ordination of the government, prioritisation will not take place optimally. Prior planning by the government should therefore focus on the co-ordination of citizen response.

\section{Disasters with Limited Possibility of Citizen Response}

A special subcategory of disasters, which can overlap with the above, is the disaster with limited capability of self reliance. Accidents on the water and aircraft accidents on airfields are examples of such disasters.

Firstly, self reliance of the citizens involved can be limited due to circumstance: in the case of accidents on water, escape routes are limited and subsequent survival on the water is largely dependent on aid from third parties. Generally, regulations are solely aimed at securing exit possibilities. The demands imposed upon licensees or recommendations to citizens are seldom aimed at the promotion of citizen response after escape.

Secondly, the possibilities for citizens to help their fellow citizens might be greatly limited in such situations: an aircraft accident on the runway, an accident on water or a train accident between the points of departure and arrival are 
examples of incidents where there are only a few possibilities for citizen response actions.

Keeping in mind the inevitably limited capacity of professional aid services, such situations in particular require previous deliberation of the promotion of citizen response. In the case of aircraft accidents, for example, a partial solution could be found in using the availability of a certain percentage of medically trained personnel among the passengers in the terminals close to potential accident areas.

The mentioned collating of disaster management processes in categories which have a similar effect on citizen response has resulted in the following (partly overlapping) sub-categorisation:

- Decision Making

- Escape

- Rescue, emergency medical aid and care in the first hours

- Relief after the first hours.

\section{Decision Making}

In all phases of a disaster or serious accident, it is necessary for all those involved (citizens and government alike) to make decisions based on the most correct information.

Citizens and government can each have access to unique information, which the other parties need. The processes must therefore be organised in such a way that such information is passed on as quickly and factual as possible. A well known example is the measurements which take place after a possible release of toxic gases: these measurements generally involve specialised emergency personnel only, and expert interpretation of the data obtained follows before the general public is informed and advised. A noxious odour, however, is generally a clue to the presence of toxic gases. Thus, in the Dutch Rotterdam-Rijnmond region the regional environmental services DCMR is already consistently using information provided by the local population: bad odours reported to the DCMR are immediately put into a data bank and actions are taken based on this. In the event of fire, too (where dangerous substances are released), the population can be informed immediately about the fact that a visible cloud is a good indication of the mere presence of substances.

\section{Escape}

When immediate evacuation of an area is necessary it should be noted that citizen response is necessary to assist the frail and elderly. Furthermore, it is important to remember that citizens will quite reasonably refuse to leave without the guaranteed safety of next of kin. These observa- tions imply that adequate instruction as preparation for disasters is necessary. This topic has been extensively researched (Perry, 1985).

\section{Rescue, Emergency Medical Aid and Care in the First Hours}

From the point of view that the capacity of relief agencies will predictably be too little in the 'golden hour of a real disaster, it seems obvious that the response of citizens will have to be incorporated in plans for acute life-saving relief as well. Case studies show that the risks are greatly outweighed by the advantages. It is assumed here as well that the average reasonable citizen will not harm himself and will also not hinder the work of the professional relief worker. As stated above, one of the first concerns raised by professional aid workers, on the topic of citizen response in relation to acute (life-saving) relief, is fear for uncoordinated behaviour and liability for injuries to citizens providing aid.

As mentioned above, there are a number of professional relief workers present amongst the average group of citizens. This group merits some more attention. At present, the planning (as regards the upscaling of hospitals) and preparation (the availability of extra relief materials) does not seem to take this group into account.

In the first hours victims have to be sheltered and taken care of. In practice, this kind of relief is mostly provided through citizens who have access to suitable locations, e.g. restaurants, neighbourhood centres etc. Case studies show a surprisingly strong tendency to centralise: emergency services attempting to move the victims to a prepared location, e.g. a community sports hall, even if this location has not been adequately prepared yet. One reason for this reaction is the wish for quick registration. In the Netherlands the Oosting Commission, which investigated the Enschede fireworks disaster, evaluated the registration procedures. It noted that the primary role of registration - helping victims find other victims - seemed to have been lost. Instead, registration became an end in itself, victims even had to wait for registration before they could enter the shelter.

\section{Relief After the First Hours}

As mentioned above, the occurrence of a disaster initiates an immediate flow of aid. Physical aid varies from teddy-bears to extra transmitters for mobile telephone services. Volunteers are available for a variety of aid services, however, they are most often only summarily used.

On the other hand, most victims demonstrate that they are proactive enough to arrange their own shelter already after the first night. Experience has shown that those who stay in the central relief centres are most often the more proble- 
matic cases, who need a lot more professional attention. Once again, planning by local and other authorities seldom takes this into account.

After the first days have passed, three different disaster management processes can be seen (Helsloot, 2003):

- Public accountability; why did the disaster happen anyway.

- Organising long term after care

- Repairing damage including establishing liability

The responding citizen will mobilise his fellow citizens and (whether asked to or not) will get involved with all three processes. For this reason, it seems desirable to involve the citizens with the formation of these three processes.

\section{Conclusions}

Citizens, at least in western societies, act as rationally in disaster situations as they do in everyday life. They do not panic, but will make rather rational decisions as to what to do and what can be done, based on the available information and time.

Citizens who do not have adequate information to assess the situation, the risks and the possible actions, might make choices that - observing from a greater distance, with more overview - may be perceived as sub-optimal. One other reason for sub-optimal choices is the great sense of loyalty of citizens to those to whom they are close.

Generally speaking, however, citizen response is what saves the day when disasters strike. Not only do citizens effectively bring themselves to safety, evaluations of disasters show that most of the victims were saved by their fellow citizens. Most of the initial aid is also provided by citizens. It is best known from the massive amount of people who come to help with aid or materials.

Up to this day, authorities have neglected the possibilities and advantages of citizen response. Most often, disaster plans generally approach the citizen as a helpless victim, who can only be helped by the appropriate services. In this context it is striking how the fear of looting following disasters recurs time and again with authorities. Although looting is actually extremely rare, the fear of it alone is enough to prevent authorities from letting citizens towards the disaster area.

Concluding from the observations above: it is necessary to take into account the possibilities of citizen response. Using this approach means that:

- the flow of information before and during disasters must be aimed at the reasonable citizen to enable him to decide for him/ herself, not to quiet his assumed fears.
- the value of citizen response for rescue needs to be taken into account, especially where emergencies services have limited capabilities to respond. Education, procedures and equipment for relief services have to be adjusted in such a way that the responding citizen will be enable to work to the maximum of his/her capacities.

- the citizen response after the acute phase, especially the process of shelter and care, should be taken more into account as well.

However prepared the citizen is for disasters, then, the act of preparation of citizens themselves is an entirely different problem. This preparation appears impossible to be stimulated, at least we know of no research which proves the opposite. In point of fact, however, the citizen is acting just as rationally and capably in this phase as in the response phase of the disaster. Where the authorities do not prepare for accidents with a sufficiently small chance of accidents occurring, the citizen too will not find preparation necessary.

Research shows that citizens will prepare for accidents of which they have the perception that preparation for it is useful, and where there is a reasonable chance they might occur. Worldwide, campaigns have proved successful in letting citizens prepare themselves for accidents such as house fires, injuries to their children or electricity failures. It seems advisable to promote this preparation of citizens, as this is a sound basis for citizen response in case of disaster.

All the above is applicable probably only for western-like societies. Much more research is needed on the effects of cultural differences.

\section{Acknowledgement}

The authors would like to thank D.E. Koops for his contribution to the translation and editing of this Article.

\section{Notes}

1. This article is based on research by COT, Institute for Crisis and Safety Management, funded by the Regional Fire Service Amsterdam and Surroundings

2. The SCP is a Dutch government agency which conducts research into the social aspects of all areas of government policy

3. Sjöberg is a well-known critic of the value of the current models, see e.g.: L. Sjöberg, 2002

4. This section is largely based on Dynes, 1994

5. For this research, the following countries were observed: Canada, US, New Zealand, Turkey, Austria and others

6. See e.g.: Commissie Onderzoek Vuurwerkramp 2001; MIPT, 2002;COT, 1993 


\section{References}

Beck, U. 1992, Risk Society: Towards a new modernity, Sage Publications, London.

Comfort, L., Tekin, A., Pretto, E., Kirimli, B. and Anges, D. (1998), 'Time, Knowledge, and Action: The Effects of Trauma Upon Community Capacity for Action', International Journal of Mass Emergencies and Disasters, 16(1), pp. 88-89.

Commissie Onderzoek Vuurwerkramp, (Research Commission on the Fireworks Disaster), (2001), 'De Vuurwerkramp: Eindrapport', Den Haag, pp. 123-124.

Dynes, R.R. and Quarantelli, E.L. (1968), 'Redefinition of property norms in community emergencies', International Journal of Legal Research, 3, 100-112.

Dynes, R.R. (1990), 'Community Emergency Planning: False Assumptions and Inappropriate Analogies', Preliminary Paper Number 145, Disaster Research Center, Univeristy of Delaware, Newark, as quoted in: Quarantelli, E.L., (1993), ' Community Crises: An Exploratory Comparison of the Characteristics and Consequences of Disasters and Riots,' Journal of Contingencies and Crisis Management, 1(2), p. 69.

Dynes, R.R. (1994), 'Community Emergency Planning: False Assumptions and Inappropriate Analogies', International Journal of Mass Emergencies and Disasters, 12(2).

Dynes, R.R. (1994), Situational Altruism: Toward an Explanation Of Pathologies in Disaster Assistance, paper presented at XIIIth World Congress of Sociology, Bielefeld.

FEMA (1999), IS 317 Introduction to Community Emergency Response Teams, at http://www.training.fema.gov/emiweb/IS/is317.asp, accessed 01 June 2004.

Fitzpatrick, C. and Mileti, D.S. (1994), 'Public Risk Communication', in: Disasters, Collective Behavior, and Social Organization, (eds), Dynes, R.R. and Tierney, K.J. pp. 73-75.

Gilbert, C. (1995), 'Studying Disaster: A Review of the Main Conceptual Tools', International Journal of Mass Emergencies and Disasters, 13(3), pp. 232.

Hashimoto, N. (2000), 'Public organizations in an emergency: the 1995 Hanshin-Awaji earthquake and municipal government', Journal of Contingencies and Crisis Management, 8(1), pp. 19.

Helsloot, I. (2003), De herstelfase; de ramp na de ramp,' Zicht op rampenbestrijding, Helsloot, I., Verhallen, P. (eds), NIBRA Publicatiereeks nr 17.

Hiroi, O. (1995), 'Earthquake Disasters: The Need for Robust Emergency Information and Transportation Networks,' The Wheel Extended, 93, p. 5.

International Federation of Red Cross and Red Crescent Societies (2001), World Disasters Report:Focus on Recovery, p. 143.

Kuipers, W. and Meuleman, H. (2003), 'Opperbevel en bestuurlijke coördinatie', Zicht op rampenbestrijding,
Helsloot, I., Verhallen, P. (eds), NIBRA Publicatiereeks nr. 17.

Lapierre, D. and Moro, J. (2001), Il était minuit cinq à Bhophal, Pressinter S.A. Major, A.M., (1999), 'Gender Differences in Risk and Communication Behavior in Response to an Earthquake Prediction, 17(3), pp. 313-338.

MIPT (2002), Oklahoma City - Seven Years Later: Lessons for Other Communities, Oklahoma.

Perry, R. and Mushkatel, A.H. (1986), Minority citizens in disasters, University of Georgia Press.

Perry, R.W. and Lindell, M.K. (2003), 'Understanding Citizen Response to Disasters with Implications for Terrorism', Journal of Contingencies and Crisis Management, 11(2), pp. 51-52.

Perry, R.W. (1985), Comprehensive Emergency Management: Evacuating Threatened Populations, pp. 66-70.

Quarantelli, E.L. and Dynes, R.R. (1969), 'Dissensus and consensus in community emergencies: patterns of looting and property norms', Il Politico, nr. 34, pp. 276-291.

Quarantelli, E.L.'How individuals and groups react during disasters: planning and managing implications for EMS delivery, DRC Prelimnary paper 138, www.udel.edu/DRC.

Quarantelli, E.L. (1993), 'Community Crises: An Exploratory Comparison of the Characteristics and Consequences of Disasters and Riots', Journal of Contingencies and Crisis Management, 1(2), p. 69.

Quarantelli, E.L. (1999), The Sociology of Panic, Disaster Research Center, University of Delaware.

Rosenthal, U., Staal, B. and Storm, K.J. (2002), Als Je Leven Je Lief Is, Max Geldens Stichting voor Maatschappelijke Vernieuwing.

Rosenthal, U. (1984), Rampen,Rellen Gijzelingen: Crisisbesluitvorming in Nederland.

Sjöberg, L. (2002), 'Are received risk models alive and well?', Risk Analysis, pp. 665-669.

Slovic, P., Fischoff, B. and Lichtenstein, S.'Rating the Risks,' Environment, 21, pp.

Sociaal en Cultureel Plan Bureau (SCP), (2002), Social Perception of External Safety.

Stallings, R and Qurantelli, E.L. (1985), 'Emergent Citizen Groups and Emergency Management', Public Aministration Review, vol 15, 93-100.

Starr, C. (1969), 'Social benefits versus technological risk', Science, 1969, pp. 1232-1238.

Thomas, W.J. and Thomas, D.S. (1928), The child in America, New York.

Tierney, K.J. (1989), 'The Social and Community Contexts of Disaster,' Gist, R. Lubin R. (1989) (eds), Psychosocial Aspects of Disaster.

Tierney, K.J. (1997), Emergency Response: Lessons Learned from the Kobe Earthquake, Disaster Research Center, University of Delaware.

Vlek, C. and Stallen, P.J. (1980), 'Rational and Personal Aspects of Risk,' 45 ACTA Psychology 273.

Wildavsky, A., Searching for Safety, New Brunswick, V.S., 1988 